\title{
Vacuum brazing of titanium alloy to stainless steel enhance by fiber laser surface texturing
}

\author{
A.J. Sulaiman H1', M.H. Aiman'1 M. Ishak', M.M Quazi' ${ }^{1}$ T. Zaharinie², T. Ariga ${ }^{3}$ \\ 1 Joining, Welding and Laser Processing Lab (JWL), Faculty of Mechanical and Automotive Engineering, Universiti Malaysia Pahang, \\ 26600 Pekan, Pahang, Malaysia \\ ${ }^{2}$ Centre of Advanced Manufacturing \& Material Processing (AMMP Centre), Department of Mechanical Engineering, Universiti Malaya, \\ 50603, Kuala Lumpur, Malaysia \\ ${ }^{3}$ Department of Material Science, School of Engineering, Tokai University, 259-1292 Kanagawa, Japan
}

\begin{abstract}
A method for improving the brazing joining strength of Titanium alloy/Stainless steel fabricated through fibre laser surface texturing is introduced because it is a simple process that does not require the fabrication of complicated interlayers. However, previous research shows that a milimeter scale was fabricated by surface modification for dissimilar brazing join, yielding insignificant results and limiting the application and degree of enhancement. Fiber laser ablation was used in this study to create microscale periodic patterns (grooves) on a stainless steel surface. No defect or damage induced during laser surface texturing process. The groove dimension was tunable by controlling the laser parameters. Vacuum brazing of Ti6AI4V to $316 \mathrm{~L}$ stainless steel with surface texturing, the average joint strength was $22.1 \mathrm{MPa}, 34 \%$ of increase of joining strength compared to unprocessed flat surface. The combination of laser surface texturing and brazing proven effectively on joining strength enhancement.
\end{abstract}

ARTICLE HISTORY

Received: $14^{\text {th }}$ Feb. 2021

Revised: $29^{\text {th }}$ Oct. 2021

Accepted: $02^{\text {nd }}$ Nov. 2021

\section{KEYWORDS}

Vacuum brazing;

titanium alloy;

dissimilar joint;

stainless steel;

geometry surface analysis; mechanical testing.

\section{INTRODUCTION}

With outstanding mechanical properties, corrosion resistance, high temperature resistance and weight reduction, dissimilar join of titanium alloy/stainless steel components attracted thriving interest in particular industries, such as aerospace repulsion system, oil pipeline and also in energy industries focusing for nuclear reactor [1,2]. Past experiments shown that some of cycles have been effectively applied to join titanium composite and treated steel, solid-state welding $[3,4]$ and fusion welding [5,6]. Because of outstanding advantages i.e economical and efficiency, brazing also more flexible in term of joint design and favourable to joint dissimilar material $[1,7,8]$.

Active brazing is a more practical method of joining dissimilar materials in which reactive elements such as $\mathrm{Ti}, \mathrm{Zr}$, $\mathrm{Hf}$, and Rf are incorporated into brazing alloys to change the chemistry of the surfaces and improve wettability and adhesion of the brazing alloy $[9,10]$. Previous studies have been carried out to investigate the active brazing for dissimilar joint, and found out there are two main challenges are often encountered [11-13]. First, to avoid the excessive formation that occurs on the interface, oversight the reaction of brazing alloy and the surfaces. Besides that, by optimize brazing parameter and modifying filler composition is another of the option to solved to issue. [14,15]. Second, mismatch of the coefficient of thermal expansion (CTE) between the materials that caused inappropriate generated residual stress between these materials. The residual stress dependently to the joint and it is frequently this residual stress will lead to the failure of the joint. Previous researchers $[14,16,17]$ share their approach on how to reduce the residual stress in dissimilar brazing joint.

The vast majority of research has focused on reducing thermal stress in dissimilar joints caused by CTE mismatch between dissimilar materials. [18]. There are three commonly used technique; (i) by adding a soft and ductile interlayer on the surfaces $[16,19]$, (ii) By incorporating an interlayer with the same CTE value between two substrates, a gradient structure in the joint is created, thereby balancing the residual stress distribution. [20] and (iii) by utilising secondary phases with a low CTE on the interlayer [21]. Despite of that, sometimes it can be quite challenging to find proper solutions. Hence, it's desirable to develop a completely unique technique or method which will optimise the residual stress distribution on dissimilar brazing joint. C. Li et al. discovered that enhanced mechanical keying via a rough interface profile is widely used in various systems to extend interface adhesion and thus component lifetime. [22], that the wobble interface could have a significant influence on residual stress distribution across the coating of materials.

As a result, it is expected that a well-designed dishevelled interface for a brazing joint will be ready to optimise residual stress distribution and bonding quality. Laser surface processing has emerged as a cutting-edge and promising technique or process for pattering ceramics and metals [23,24]. Y. Zhang et al. conducted research to modify the surface morphology of ceramic for dissimilar brazing [18], surface processing on an alumina surface with a femtosecond laser yielded grooves less than $100 \mathrm{~m}$ deep. The strength of a stainless steel joint is approximately 2.7 times greater than that of a flat surface. The effect of laser power on joint strength was studied, and the optimal laser power was determined to 
be $0.3 \mathrm{~W}$. The results showed that laser surface patterning increased joint strength significantly when compared to an unprocessed flat surface.

A new technique for modifying the surface of a dissimilar brazing joint, Titanium alloy/Stainless steel, and improving joining quality via fibre laser surface texturing is introduced in this study. Furthermore, fibre lasers are thought to be the best type used in industry. [25]. It is investigated how machined surface morphology affects joint mechanical properties. The effect of surface machining on stress distribution during shear testing in the brazing joint is investigated using optical images and 3D laser scanning.

\section{METHODS AND MATERIALS}

The base metals to be brazed in this study were Ti6Al4V alloy and 316L SS with the chemical composition of Ti5.9Al-3.6V (wt.\%) and Fe-16.5Cr-10.2Ni-2.0Mo-1.3 Mn (wt.\%), respectively shown in Table 1. Prior to brazing, the base metals were cut into the dimension of $5 \mathrm{~mm}$ with diameter of $6 \mathrm{~mm}$ for Ti rod and 60mm x 10mm for SS plate by precision diamond cut as shown in Figure 1. AgCuTi alloy were used as brazing filler metallic alloy. Chemical composition and temperature were shown in Table 2 . The faying surfaces of base metal were polished with $600 \#$ to $800 \#$ grit SiC papers then both base and filler metal ultrasonically cleaned in acetone solution for about $5 \mathrm{~min}$.

Table 1. Chemical compositions of base metal

\begin{tabular}{cccccccccc}
\hline \multirow{2}{*}{ Materials } & \multicolumn{10}{c}{ Chemical composition (wt.\%) } \\
\cline { 2 - 11 } & $\mathrm{Ti}$ & $\mathrm{Al}$ & $\mathrm{V}$ & $\mathrm{Fe}$ & $\mathrm{C}$ & $\mathrm{Mn}$ & $\mathrm{Mo}$ & $\mathrm{Cr}$ & $\mathrm{Ni}$ \\
\hline Titanium alloy (Ti4V6Al) & $\mathrm{Bal}$ & 5.5 & 4.5 & - & - & - & - & - & - \\
Stainless Steel (316 L) & - & - & - & Bal. & 0.03 & 2.0 & 2.0 & 17.0 & 12.0 \\
\hline
\end{tabular}

Table 2. Chemical compositions and temperature of filler metal

\begin{tabular}{ccccc}
\hline \multicolumn{3}{c}{ Chemical Compositions, $($ wt. \%) } & \multicolumn{2}{c}{ Temperature, ${ }^{\circ} \mathrm{C}$} \\
Filler & $\mathrm{Ag}$ & $\mathrm{Cu}$ & $\mathrm{Ti}$ & Liquidus \\
BAg-Ti & 71.25 & 27.25 & 1.5 & 790 \\
\hline
\end{tabular}

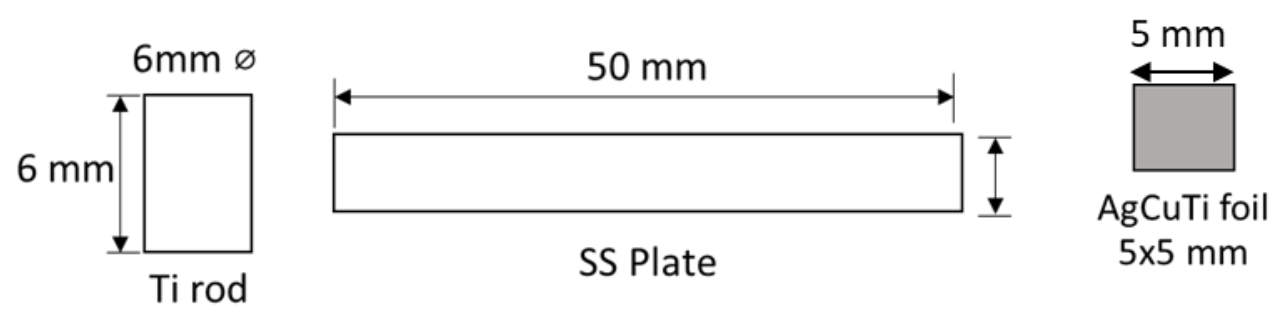

Figure 1. Schematic dimension for each sample and filler metal

An ultra-fast fibre laser system was used to create periodic surface groove structures on stainless-steel samples. The fibre laser had a wavelength of $1064 \mathrm{~nm}$, a maximum speed of $3000 \mathrm{~mm} / \mathrm{s}$, a maximum frequency of $300 \mathrm{kHz}$, and a precision of 1 micrometre. The laser beam had a diameter of 50 micrometres and was focused by a $186 \mathrm{~mm}$ focal length lens, as shown in Table 3. The surface modification experiments were carried out in air, and the distance between grooves is constant at $100 \mathrm{~m}$, as shown in Figure 2 of the schematic diagram. A confocal laser scanning microscope was used to measure the surface profilers (Olympus, LEXT).

Table 3. Parameter for laser surface modification

\begin{tabular}{cc}
\hline Laser Parameters & Values \\
\hline Power $(\mathrm{W})$ & $27(90 \%)$ \\
Speed $(\mathrm{mm} / \mathrm{s})$ & 500 \\
Operational mode & Loop: 5 \\
Frequency $(\mathrm{kHz})$ & 20 \\
Focus length $(\mathrm{mm})$ & 186 \\
\hline
\end{tabular}




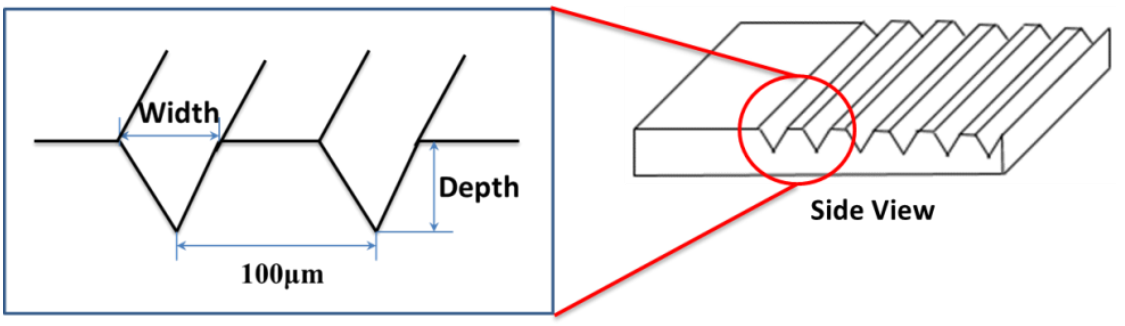

Figure 2. Schematic diagram for surface texturing on SS

In a vacuum of $1.0 \times 10^{-2} \mathrm{~Pa}$, the joints were brazed with consistent parameters. The temperature profile was heating to 700 degrees Celsius at 10 degrees Celsius per minute and holding for 5 minutes; heating to 850 degrees Celsius at 5 degrees Celsius per minute and holding for 5 minutes; and finally cooling the inside furnace to room temperature. The temperature profile for the brazing process is depicted in Figure 3. Shear testing at room temperature with a constant speed of $3 \mathrm{~mm} / \mathrm{min}$ was used to assess joint strength. Each data set contained an average of 3-5 samples. An optical microscope and laser scanning measurements were used to examine the fracture surface of the joint. Figure 4 depicts a typical brazed joint as well as a shear test schematic diagram. An optical microscope was used to examine the fracture surface of the sample.

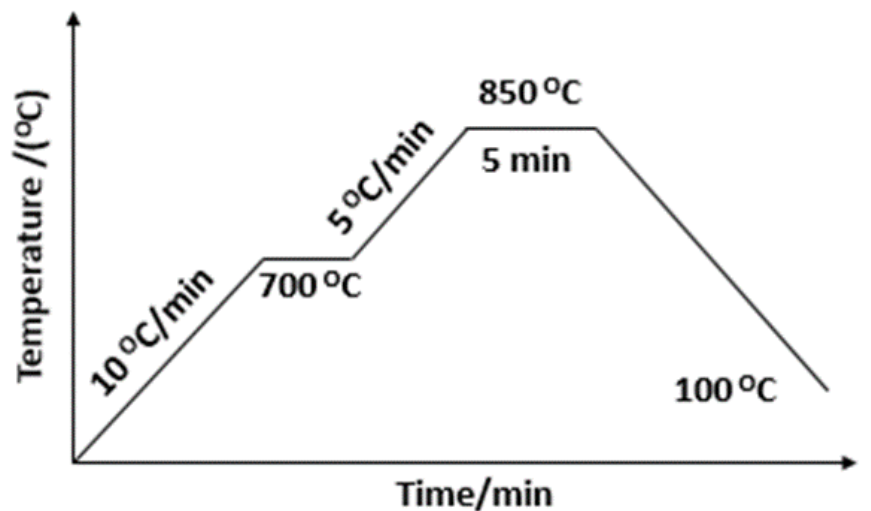

Figure 3. Temperature profile for brazing process

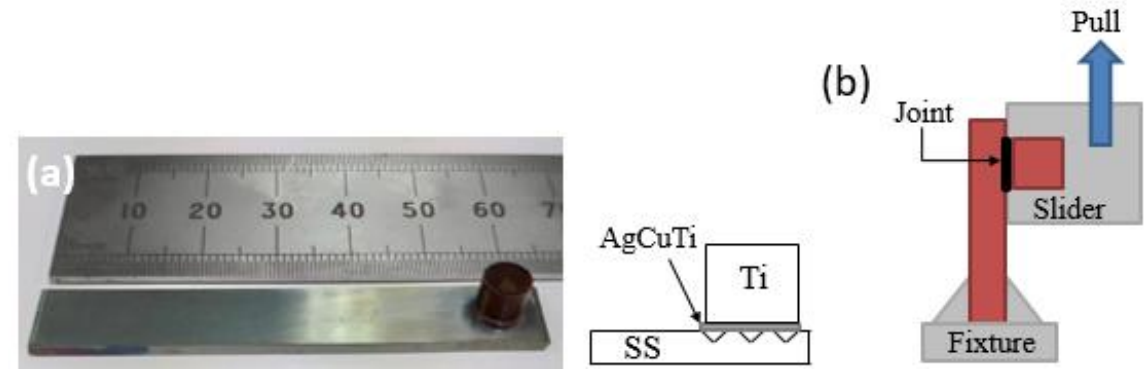

Figure 4. (a) Illustration of a typical joint and (b) Schematic of a shear test

\section{RESULTS AND DISCUSSION}

On the SS surface, periodic groove structures were created using fibre laser ablation. As a constant, the distance between each parallel groove was set to $100 \mathrm{~mm}$. Figure 4 shows that the ablated surface was smooth, with no visible cracks or pores. Because of inherent advantages such as compactness, high pulse quality, and alignment freedom, fibre lasers are quite well known to be passive mode-locking. [26]. In this study, the laser power density at the focal point was far above the SS ablation threshold. Because the majority of the energy was removed during the ablation reaction, the heat effect was minimised, preventing crack formation. Furthermore, the laser pulse width $\left(10^{-15} \mathrm{~s}\right)$ was much shorter than the heat transfer time $\left(10^{-12} \mathrm{~s}\right)$, resulting in precise ablation [27].

Figure 5 depicts an optical image of the as-fabricated textured surface taken with a confocal laser scanning microscope at a depth of $73 \mathrm{~m}$. Figure 5(c) also shows the corresponding analysis for textured surface, which shows the depth of the grooves, height, and distance for each groove. Although the fabricated groove structure's alignment is regular, the form accuracy is not perfectly uniform due to minor differences in the bottom morphologies of neighbouring grooves. 


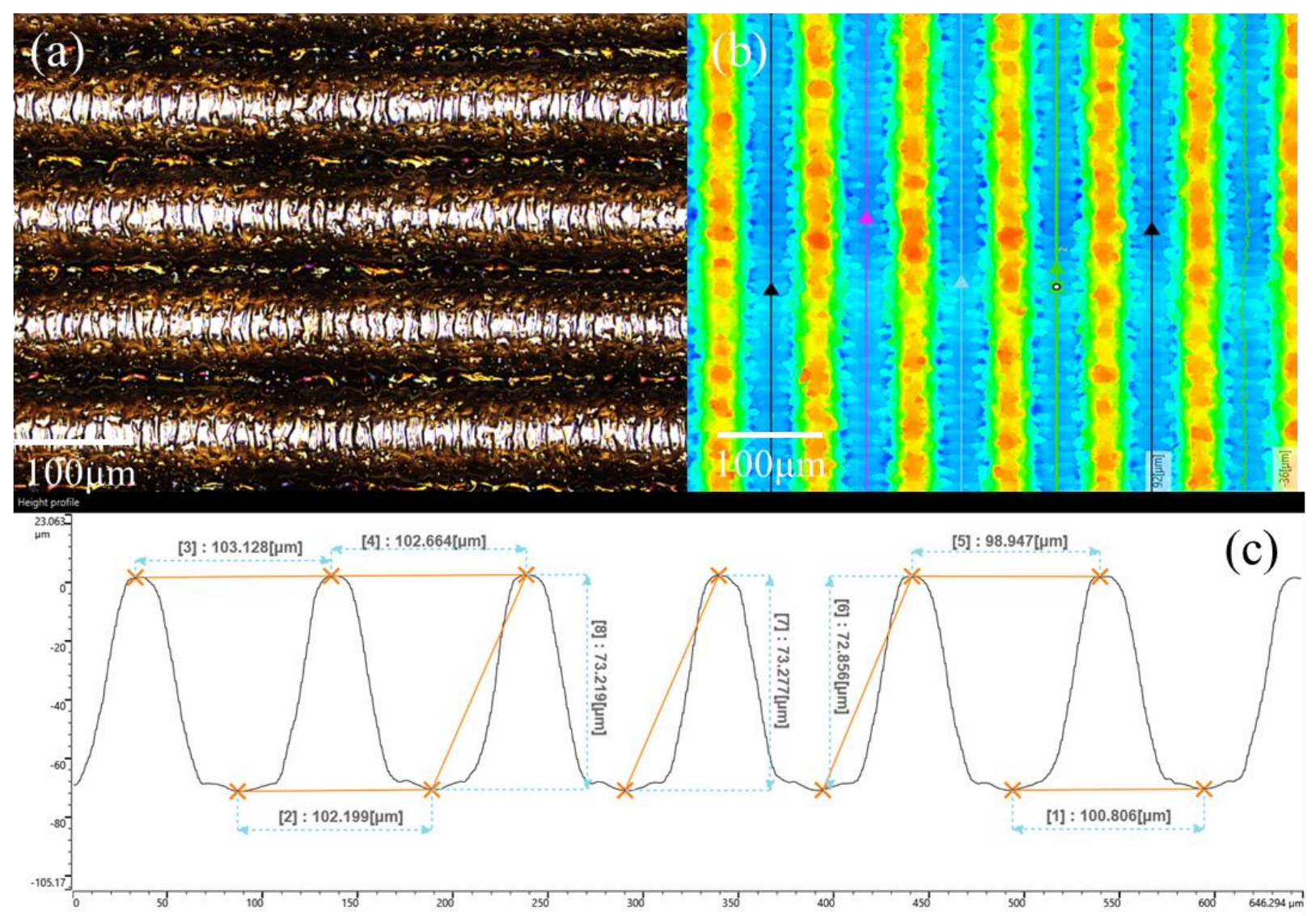

Figure 5. (a) Optical image of laser surface textured, (b) Confocal analysis laser scanning image and (c) Cross-section profile plot
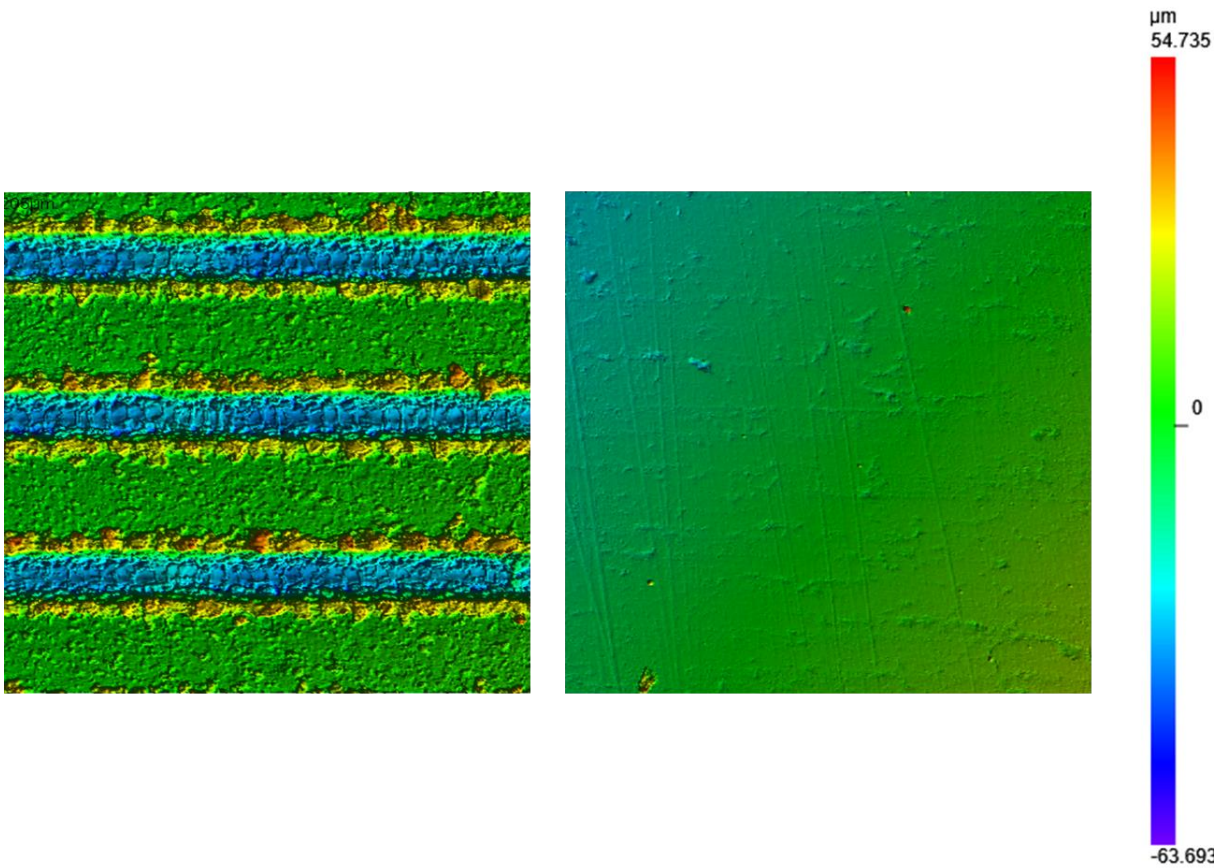

Figure 6. 3D image of the groove structure surface and unprocessed surface

Figure 7 depicts the shear strength of a brazed joint at various surface conditions. In the graph, normal brazing is represented by an untreated surface. The shear test was performed along the groove's perpendicular direction. The results clearly demonstrated that joint strength was highly related to the surface condition, in this case laser power. The maximum shear strength of the laser-patterned joints was 1.5 times greater than that of the flat surface joints (31.38 MPa). When the shear strength of the brazed joint is compared to the shear strength of the original flat surface brazing, the shear strength of the brazed joint with modified surface using high laser power is higher, indicating that the bonding strength 
of the brazed interface is strong. Surface modification clearly increases shear strength by approximately $35 \%$, as shown in the graph.

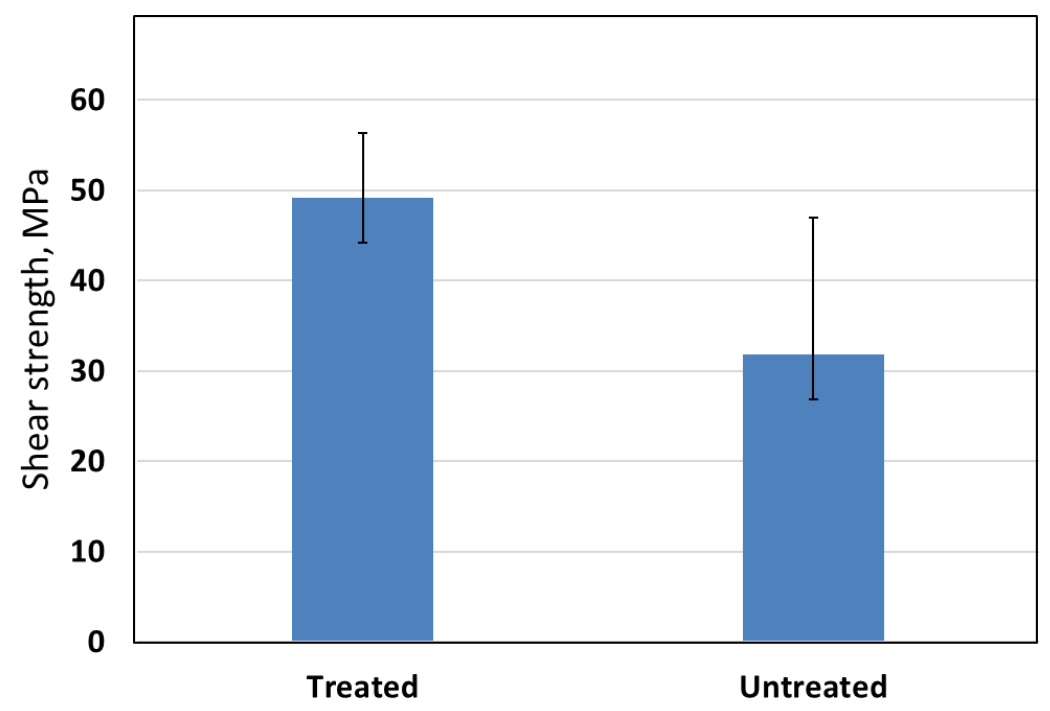

Figure 7. Shear strength between untreated and laser textured surface

Figure 7 depicts the spreading of the filler and the fracture of the brazed joint for both the original flat surface and the modified surface. For Figure 7(a), the filler metal only spread on area contact of the joint while for modified surface, Figure 7(b), the filler flow along the modified surface area, which larger that original flat surface. Visual inspection revealed two fracture modes: SS fracture through the SS surface and interfacial fracture along the braze interface, as shown in Figures 7(a) and (b). The fracture or necking occurs at the base SS metal due to high shear strength, as shown in Figure 7(b). Furthermore, the filler spread is much wider than on the original flat surface. The joint strength will be lower than expected if the filler material does not completely fill the joining area. For example, if the surface is not modified, the wettability suffers, and the filler metal cannot spread throughout the joining area because it is solely dependent on the surface condition. The spread of filler metal on the brazed area is one of the critical factors that contribute to mechanical joining strength.

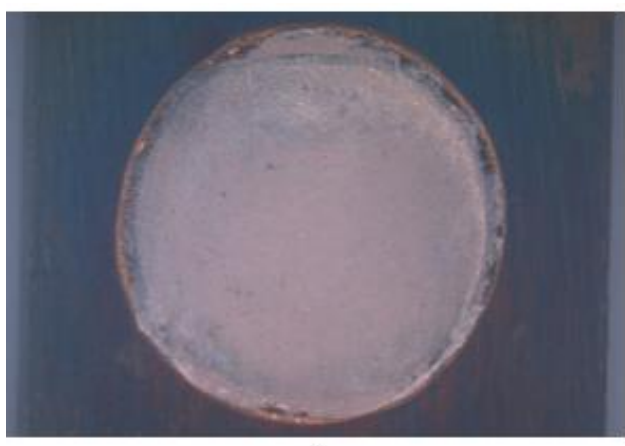

a)

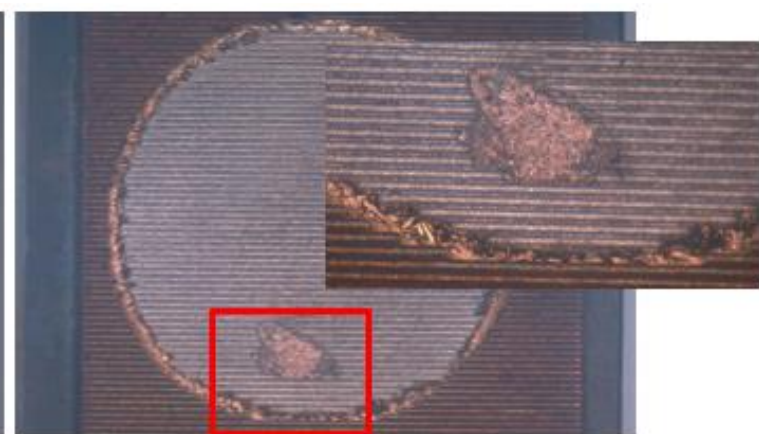

b)

Figure 7. Surface of fracture; (a) original flat surface and (b) modified surface

\section{CONCLUSIONS}

The strength of the hybrid brazed joint has been significantly enhanced by fibre laser surface modifications on the metal. The main conclusions are:

1. The dimensions of the grooves surface structures could be tuned by adjusting laser parameters. The heat effect was minimised by the fibre laser's cold-processing nature, and no defects on the base material were observed.

2. Surface modification had a strong influence on joint strength. It is caused by the molten filler spreading on the joining area. It demonstrates that using laser surface modification can increase joint strength by $35 \%$.

3. It can be observed that the by using laser to modified surface material, can significantly reduce the dispersion in the results and improving the dependability of the joint. 


\section{ACKNOWLEDGMENTS}

The authors would like to thank to the Ministry of Education Malaysia and University Malaysia Pahang for laboratory facilities and financial assistance under Research Grant Project RDU1902608 (RACER/1/2019/TK03/UMP//3), RDU1903118, PGRS1903175 and Kotaro Matsu from Tokyo Braze Co. Ltd for providing brazing filler materials. Also, laboratory facilities support such as high vacuum furnace from Centre of Advance of Manufacturing and Materials processing (AMMP), University Malay and 3D measuring laser microscope from Faculty of Manufacturing and Mechatronic Engineering Technology of University Malaysia Pahang, are gratefully acknowledge.

\section{REFERENCES}

[1] Y. Xia et al., "Interfacial microstructure and shear strength of Ti6Al4V alloy/316 L stainless steel joint brazed with Ti33.3Zr16.7Cu50-xNix amorphous filler metals," Mater. Des., vol. 187, p. 108380, 2020.

[2] Y. Xia, P. Li, X. Hao, and H. Dong, "Interfacial microstructure and mechanical property of TC4 titanium alloy/316L stainless steel joint brazed with Ti-Zr-Cu-Ni-V amorphous filler metal," J. Manuf. Process., vol. 35, no. July, pp. 382-395, 2018.

[3] P. Li et al., "Inhomogeneous interface structure and mechanical properties of rotary friction welded TC4 titanium alloy/316L stainless steel joints," J. Manuf. Process., vol. 33, no. May, pp. 54-63, 2018.

[4] B. Li et al., "Effect of titanium grain orientation on the growth of compounds at diffusion bonded titanium/steel interfaces," Mater. Charact., vol. 148, no. July 2018, pp. 243-251, 2019.

[5] X. Hao, H. Dong, S. Li, X. Xu, and P. Li, "Lap joining of TC4 titanium alloy to 304 stainless steel with fillet weld by GTAW using copper-based filler wire," J. Mater. Process. Technol., vol. 257, no. January, pp. 88-100, 2018.

[6] Y. Zhang, D. Q. Sun, X. Y. Gu, Z. Z. Duan, and H. M. Li, "Nd:YAG pulsed laser welding of TC4 Ti alloy to 301L stainless steel using Ta/V/Fe composite interlayer," Mater. Lett., vol. 212, pp. 54-57, 2018.

[7] A. J. H. Sulaiman, W. N. W. M. Hissyam, M. H. Aiman, M. Ishak, and T. Ariga, "Effect of copper based filler composition on the strength of brazed joint," J. Mech. Eng. Sci., vol. 13, no. 2, pp. 5090-5103, 2019.

[8] W. N. W. M. N. Hissyam, A. M. Halil, T. Kurniawan, M. Ishak, and T. Ariga, "Effect of Copper-based Fillers Composition on Spreading and Wetting Behaviour," IOP Conf. Ser. Mater. Sci. Eng., vol. 238, no. 1, 2017.

[9] O. Kozlova, M. Braccini, R. Voytovych, N. Eustathopoulos, P. Martinetti, and M.-F. Devismes, "Brazing copper to alumina using reactive CuAgTi alloys," Acta Mater., vol. 58, no. 4, pp. 1252-1260, 2010.

[10] A. Laik, P. Mishra, K. Bhanumurthy, G. B. Kale, and B. P. Kashyap, "Microstructural evolution during reactive brazing of alumina to Inconel 600 using Ag-based alloy," Acta Mater., vol. 61, no. 1, pp. 126-138, 2013.

[11] I. V Fedotov, A. N. Suchkov, O. V Sevryukov, A. A. Ivannikov, P. S. Gasnikov, and S. N. Sannikova, "Brazing of zirconiabased ceramics to $29 \mathrm{NK}$ alloy using CTEMET 1202 amorphous tape brazing alloy," Weld. Int., vol. 31, no. 12, pp. 979-983, Dec. 2017.

[12] M. Ali, K. M. Knowles, P. M. Mallinson, and J. A. Fernie, "Interfacial reactions between sapphire and Ag-Cu-Ti-based active braze alloys," Acta Mater., vol. 103, pp. 859-869, 2016.

[13] F. Moszner, G. Mata-Osoro, M. Chiodi, J. Janczak-Rusch, G. Blugan, and J. Kuebler, "Mechanical behavior of SiC joints brazed using an active Ag-Cu-In-Ti braze at elevated temperatures," Int. J. Appl. Ceram. Technol., vol. 14, no. 4, pp. 703-711, Jul. 2017.

[14] P. Wang, D. Xu, Y. Zhai, and J. Niu, "The dissimilar brazing of Kovar alloy to SiCp/Al composites using silver-based filler metal foil," Appl. Phys. A Mater. Sci. Process., vol. 123, p. 569, Sep. 2017.

[15] Q. Zhang, L. Sun, Q. Liu, J. Zhang, T. Wang, and C. Liu, "Effect of brazing parameters on microstructure and mechanical properties of $\mathrm{Cf} / \mathrm{SiC}$ and $\mathrm{Nb}-1 \mathrm{Zr}$ joints brazed with Ti-Co-Nb filler alloy," J. Eur. Ceram. Soc., vol. 37, no. 3, pp. 931-937, 2017.

[16] T. Wang, T. Ivas, W. Lee, C. Leinenbach, and J. Zhang, "Relief of the residual stresses in Si3N4/Invar joints by multi-layered braze structure - Experiments and simulation," Ceram. Int., vol. 42, no. 6, pp. 7080-7087, 2016.

[17] A. J. Sulaiman, M. H. Aiman, M. M. Quazi, M. Ishak, and T. Ariga, "Enhancement of mechanical properties of Copper Brazed by laser surface modification," IOP Conf. Ser. Mater. Sci. Eng., vol. 788, no. 1, 2020.

[18] Y. Zhang, G. Zou, L. Liu, A. Wu, Z. Sun, and Y. N. Zhou, "Vacuum brazing of alumina to stainless steel using femtosecond laser patterned periodic surface structure," Mater. Sci. Eng. A, vol. 662, pp. 178-184, 2016.

[19] X. Wang, C. Li, X. Si, J. Qi, J. Feng, and J. Cao, “Brazing ZTA ceramic to TC4 alloy using the Cu foam as interlayer," Vacuum, vol. 155 , pp. 7-15, 2018.

[20] J. M. Fernandez, R. Asthana, M. Singh, and F. M. Valera, "Active metal brazing of silicon nitride ceramics using a Cu-based alloy and refractory metal interlayers," Ceram. Int., vol. 42, no. 4, pp. 5447-5454, 2016.

[21] Y. H. Zhou, D. Liu, H. W. Niu, X. G. Song, X. D. Yang, and J. C. Feng, "Vacuum brazing of C/C composite to TC4 alloy using nano-A12O3 strengthened AgCuTi composite filler," Mater. Des., vol. 93, pp. 347-356, 2016.

[22] C. Li et al., "Precise strain profile measurement as a function of depth in thermal barrier coatings using high energy synchrotron X-rays," Scr. Mater., vol. 113, pp. 122-126, 2016.

[23] C. Li et al., "Understanding the effect of surface machining on the YSZ/Ti6Al4V joint via image based modelling," Sci. Rep., vol. 9, no. 1, pp. 1-13, 2019. 
[24] M. N. M. Salleh, M. Ishak, M. H. Aiman, Q. Zaifuddin, and M. M. Quazi, "The effect of laser surface hardening on the surface hardness of mild steel," IOP Conf. Ser. Mater. Sci. Eng., vol. 788, no. 1, 2020.

[25] M. N. M. Salleh, M. Ishak, F. R. M. Romlay, and M. H. Aiman, "A study on bead-on-plate welding of AA7075 using low power fiber laser," J. Mech. Eng. Sci., vol. 10, no. 2, pp. 2065-2075, 2016.

[26] C. Shang et al., "Review on wavelength-tunable pulsed fiber lasers based on 2D materials," Opt. Laser Technol., vol. 131, no. May, 2020.

[27] D. Ashkenasi, A. Rosenfeld, H. Varel, M. Wähmer, and E. E. B. Campbell, "Laser processing of sapphire with picosecond and sub-picosecond pulses," Appl. Surf. Sci., vol. 120, no. 1, pp. 65-80, 1997. 